\title{
GAMBARAN PRURITUS UREMIK PASIEN GAGAL GINJAL KRONIK DI UNIT HEMODIALISA RUMAH SAKIT UMUM PUSAT HAJI ADAM MALIK MEDAN
}

\author{
Friska Sembiring $^{1 *}$, Siti Saidah Nasution ${ }^{2}$, Yesi Ariani ${ }^{2}$ \\ ${ }^{1,2,3}$ Magister Keperawatan, Universitas Sumatera Utara \\ Jl. , Prof. Maas No. 3, Medan, Indonesia \\ E-mail: Friskakembaren09@gmail.com
}

\begin{abstract}
Abstrak
Pruritus uremik merupakan salah satu keluhan yang sering terjadi pada pasien gagal ginjal kronik yang merupakan sensasi tidak nyaman atau rasa gatal dan dapat menyebabkan gangguan pada siang atau malam hari bahkan dapat terjadi sepanjang hari seperti gangguan tidur, beraktifitas, depresi dan komplikasi pada kulit yang dapat menurunkan kualitas hidup pasien gagal ginjal kronik. Penelitian ini bertujuan untuk melihat gambaran pruritus uremik yang dialami pasien gagal ginjal kronik dengan menggunakan design kuantitatif deskriptif. Instrumen yang digunakan dalam penelitian ini adalah data demografi dan kuesioner 5-D itch scale (skala gatal). Penelitian ini dilakukan di Rumah Sakit Umum Pusat Haji Adam Malik Medan dalam waktu satu bulan dengan jumlah sampel 49 orang. Hasil penelitian karakteristik responden menggambarkan mayoritas lansia (26,5\%) yang menderita uremik pruritus, jenis kelamin laki-laki $(61,2 \%)$, sudah mengalami uremik pruritus lebih dari 6 minggu (100\%), mayoritas sudah menjalani hemodialisa > 1 tahun $(79,6 \%)$ dan mayoritas sudah tidak bekerja (73,5\%) serta penyakit hipertensi merupakan mayoritas penyakit penyerta (73,5\%) dengan hasil skala gatal 15-24 (sedang) sebanyak 59,2\%. Penelitian ini memberikan beberapa informasi faktor yang menjadi penyebab dan yang memperparah kejadian pruritus uremik pada pasien gagal ginjal kronik sehingga perawat dapat lebih maksimal dalam melakukan asuhan keperawatan pada pasien yang mengalami pruritus uremik khususnya pada pasien gagal ginjal kronik.
\end{abstract}

Kata kunci: gagal ginjal kronik; hemodialisa; pruritus uremik

\begin{abstract}
Uremic pruritus is one of patient's complaint about chronic kidney disease which is an uncomfortable and itchy sensation and can cause disturbances during the day or night and can even occur throughout the day such as sleep disturbance, activity, depression and complications in the skin that can reduce the quality of life of patients with chronic kidney failure. This study aims to look at the description of uremic pruritus experienced by patients with chronic kidney failure using descriptive quantitative design. The instruments used in this study were demographic data and a 5-D itch scale questionnaire. This research was conducted at the General Hospital of Haji Adam Malik Medan in one month with a sample of 49 people. The results of the study of the characteristics of respondents describe the majority of elderly (26.5\%) who suffer from uremic pruritus, male gender (61.2\%), have experienced uremic pruritus for more than 6 weeks (100\%), the majority have undergone hemodialysis $>1$ year $(79.6 \%)$ and the majority are no longer working (73.5\%) and hypertension is the majority of concomitant diseases (73.5\%) with an itching scale of 15-24 (moderate) of 59.2\%. This study provides some information on the factors that cause and that aggravate the incidence of uremic pruritus in patients with chronic renal failure so that nurses can get more leverage in nursing care for patients with uremic pruritus, especially in patients with chronic kidney failure.
\end{abstract}

Keywords: Uremic Pruritus; Chronic Kidney Disease; Hemodialysis 


\section{Pendahuluan}

Gagal ginjal terjadi ketika ginjal tidak dapat mengeluarkan limbah metabolisme tubuh atau menjalankan fungsi pengaturannya, salah satu dari jenis gagal ginjal yaitu gagal ginjal kronik yang merupakan terjadinya kerusakan fungsi ginjal yang terjadi bertahuntahun, bersifat progresif dan irreversibel tanpa memperhatikan penyebabnya (Smeltzer \& Bare, 2010).

Terapi hemodialisa adalah proses terjadinya difusi partikel yang terlarut dan air secara pasif yang dilakukan melalui kompartemen cair yaitu darah menuju kompartemen dialisat melewati membran semi permeabel dalam dializer dan sampai saat ini masih diberikan kepada pasien gagal ginjal kronik untuk mempertahankan fungsi ginjal yang telah rusak seperti menghilangkan gejala uremia, kelebihan cairan tubuh dan untuk keseimbangan pada elektrolit tubuh, dimana hemodialisa adalah (Price \& Wilson, 2015).

Banyak keluhan yang dapat dirasakan oleh pasien gagal ginjal kronik seperti kelelahan, kelemahan otot, kulit kering dan insomnia serta salah satu keluhan lainnya adalah uremik pruritus (UP) yang merupakan sensasi tidak nyaman atau rasa gatal yang dapat menurunkan kualitas hidup pasien yang menjalani terapi hemodialisa dan ditemukan lebih dari $40 \%$ pasien yang menjalani terapi hemodialisa mengalami uremik pruritus (Nakhee, 2015; Curcani \& Tan, 2014).

Uremik pruritus (UP) memiliki penyebab yang multifaktor yang berarti memiliki banyak faktor penyebab. Intensitas dan distribusi spasial oleh pruritus terjadi sangat signifikan dari waktu ke waktu dan pasien dengan tingkatan yang lebih bervariasi dan dipengaruhi oleh lama terjadinya gangguan ginjal (Abdelghfar et al, 2017) dan uremik pruritus yang berat dapat meningkatkan angka kematian pada pasien yang menjalani terapi hemodialisa (Combs et al, 2015).

Efek yang sangat signifikan juga terlihat pada status fisik, sosial dan psikologis yang dapat terjadi pada pasien yang menjalani terapi hemodialisa akibat dari pruritus yang dialami sehingga menimbulkan eksoriasis karena terus menerus menggaruk, infeksi, lesi kronis pada kulit hingga kelelahan kronis yang berhubungan dengan pola tidur baik siang maupun malam dan memberikan efek yang negatif untuk mental bahkan fisik penderita gagal ginjal kronik (Abdelgafar et al. 2017).

Pruritus uremik sering dikaitkan sebagai penyebab kematian pada penderita gagal ginjal kronik dimana pruritus uremik dapat mengganggu kualitas hidup bahkan dapat meningkatkan mortalitas pada penderita dan gejala ini menjadi gangguan kulit yang paling sering dan terjadi pada penyakit sistemik, kejiwaan (Reich \& Szepietowski, 2013).

Patogen dari pruritus pada gagal ginjal kronik sulit untuk dipahami banyak studi yang menunjukkan bahwa selain faktor metabolik dan pembersihan dialisis, peradangan juga merupakan faktor yang terkait pada pasien yang menjalani rawat inap yang mendapatkan transfusi darah dan berbagai penelitian menunjukkan faktor yang berbeda-beda sehingga sangat sulit untuk emnemukan perawatan yang tepat untuk mengatasi pruritus uremik yang dialami oleh pasien (Yan Cui et al, 2015).

Sebuah penelitian longitudinal menemukan bahwa UP umumnya kecil terjadi pada pasien yang baru akan memulai hemodialisa dari pada pasien yang menjalani dialisis sudah lebih dari 3 bulan dan yang mengalami pruritus sedang sampai skala berat terjadi sebanyak $42 \%$ pada pasien hemodialisa. National Chronic Kidney Disease Fact Sheet (2017) menyatakan bahwa di negara Amerika Serikat pada tahun 2014 sebanyak 118.000 orang yang menjalani pengobatan gagal ginjal kronik baik transplantasi maupun terapi dialisis dan 662.000 orang yang menjalani terapi hemodialisa, sedangkan di Indonesia menurut Riskesdas (2017) sejak tahun 2007 terjadi peningkatan jumlah pasien yang menjalani terapi hemodialisa dengan prevalensi angka tahun 2016 di Indonesia adalah 52.835 orang untuk pasien yang aktif menjalani terapi dan jumlah pasien baru menderita sebanyak 25.446 orang. Dari data rekam medis RSUP Haji Adam Malik Medan di dapatkan pasien menjalani terapi hemodialisa pada tahun 2016 sebanyak 275 orang dan tahun 2017 sebanyak 293 orang.

Melihat dari dampak dan penyebab yang disebabkan oleh uremik pruritus, maka peneliti tertarik untuk mengetahui gambaran penderita gagal ginjal kronik yang mengalami pruritus uremik.

\section{Metode Penelitian}

Penelitian ini adalah kuantitatif deskriptif dengan populasi dalam penelitian ini adalah seluruh pasien gagal ginjal kronik di RSUP Haji Adam Malik Medan berjumlah 727 orang yang dilakukan pada bulan AprilMei 2019 dan sampel dalam penelitian ini berjumlah 49 responden yang telah di hitung menggunakan power analysis dengan pengambilan sampel menggunakan non probability sampling dengan tekhnik consecutive sampling.

Penelitian ini telah mendapat persetujuan etik dari Komisi Etik Penelitian Kesehatan Fakultas Keperawatan Universitas Sumatera Utara (No Registrasi 1668/III/SP/2019).

Penelitian ini menggunakan kuesioner 5-D Itch Scale (Skala Gatal) yang ditemukan oleh Elman et al. (2010) yang terdiri dari 5 dimensi pertanyaan yaitu degree (derajat), duration (durasi), direction (perkembangan rasa gatal), disability (gangguan beraktifitas akibat gatal) dan distribution (lokasi rasa gatal) dengan penilaian 0-5 (tidak ada), 6-14 (ringan), 15-24 (sedang), 25-35 (berat) yang telah dilakukan validasi dan reliabilitas dengan nilai $C V I 0.90$ dan hasil 
koefisien reliabilitas dengan Cronbach's alpa 0.97 sehingga instrumen layak digunakan.

\section{Hasil Penelitian}

Karakteristik responden dalam penelitian ini mayoritas usia lansia awal (46-55 tahun) dan lansia akhir (56-65 tahun) masing-masing dengan persentase $26,5 \%$, jenis kelamin pria $61,2 \%$, berdasarkan lama mengalami pruritus mayoritas diatas 6 minggu $100 \%$ serta lama menjalani hemodialisa mayoritas lebih dari 1 tahun dengan persentase 39\%, mayoritas pendidikan terakhir SMA 49\%, mayoritas tidak bekerja 73,5\% dan mayoritas penyakit penyerta adalah hipertensi $73,5 \%$. Karakteristik responden dapat dilihat dari tabel 1 dibawah ini. 
Tabel 1. Distribusi Frekuensi dan persentase karakteristik responden

\begin{tabular}{|c|c|c|}
\hline Karakteristik & Frekuensi & Persentase (\%) \\
\hline \multicolumn{3}{|l|}{ Jenis Kelamin } \\
\hline Laki-Laki & 30 & 61.2 \\
\hline Perempuan & 19 & 38.8 \\
\hline \multicolumn{3}{|l|}{ Usia } \\
\hline 17-25 tahun & 3 & 6.1 \\
\hline 26-35 tahun & 7 & 14.3 \\
\hline 36-45 tahun & 9 & 18.4 \\
\hline 46-55 tahun & 13 & 26.5 \\
\hline 56-65 tahun & 13 & 26.5 \\
\hline \multicolumn{3}{|l|}{ Lama Pruritus } \\
\hline$>6$ minggu & 49 & 100 \\
\hline$<6$ minggu & 0 & 0 \\
\hline \multicolumn{3}{|l|}{ Lama Hemodialisa } \\
\hline 3 bulan & 1 & 2 \\
\hline 6 bulan & 0 & 0 \\
\hline 1 tahun & 9 & 18.4 \\
\hline$>1$ tahun & 39 & 79.6 \\
\hline \multicolumn{3}{|l|}{ Pekerjaan } \\
\hline Tidak Bekerja & 36 & 73.5 \\
\hline Wiraswasta & 7 & 14.3 \\
\hline Petani & 1 & 2.0 \\
\hline PNS & 5 & 10.2 \\
\hline \multicolumn{3}{|l|}{ Pendidikan Terakhir } \\
\hline $\mathrm{SD}$ & 9 & 18.4 \\
\hline SMP & 7 & 14.3 \\
\hline SMA & 24 & 49.0 \\
\hline Perguruan Tinggi & 9 & 18.4 \\
\hline \multicolumn{3}{|l|}{ Riwayat Penyakit Lainnya } \\
\hline Hipertensi & 36 & 73.5 \\
\hline DM & 9 & 18.4 \\
\hline DM+Gout Artritis & 1 & 2 \\
\hline Gout Artritis & 2 & 4.1 \\
\hline DM+Hipertensi & 1 & 2 \\
\hline
\end{tabular}

Tabel 2. Analisa sebelum diberikan Aromaterapi: Peppermint Pada Pasien Gagal Ginjal Kronik Yang Menjalani Terapi Hemodialisa $(n=49)$

\begin{tabular}{ccc}
\hline Skor & $f$ & $\%$ \\
\hline 0-5 (tidak ada) & 0 & 0 \\
6-14 (ringan) & 12 & 59.52 \\
15-24 (sedang) & 29 & 16.32 \\
25-35 (berat) & 8 & \\
& & 100 \\
\hline Total & 49 & \\
\hline
\end{tabular}


Berdasarkan tabel diatas bahwa mayoritas responden mengalami uremik pruritus pada skala sedang $59,2 \%$.

\section{Pembahasan}

Penelitian ini memperoleh hasil skala pruritus uremik dengan skala pruritus uremik yang dialami responden mayoritas adalah 15-24 (sedang) dengan frekuensi hemodialisa dilakukan dua kali dalam seminggu karena dengan memberikan tindakan hemodialisa yang adekuat serta terkontrol dapat mengurangi uremik didalam darah dan kejadian uremik pruritus dapat lebih dikurangi, sehingga didapatkan bahwa responden yang teratur melakukan hemodialisa dapat membantu meringankan kejadian uremik pruritus (Marthur et al, 2010).

Dalam pernyataan Germain (2017) bahwa lebih dari $40 \%$ penderita gagal ginjal kronik (gagal ginjal tahap akhir) yang menjalani hemodialisa mengalami uremik pruritus dimulai dari derajat sedang hingga derajat berat.

Hemodialisa yang telah dilakukan dalam waktu yang lebih lama bahkan sampai bertahun-tahun dapat meningkatkan kejadian uremik pruritus (Germain, 2017; Lin et al, 2012), sesuai dengan hasil penelitian yang didapatkan bahwa mayoritas responden yang mengalami uremik pruritus adalah responden yang sudah bertahuntahun menjalani hemodialisa (lebih dari satu tahun). Tetapi penelitian ini tidak sejalan dengan hasil penelitian yang dilakukan oleh Tarp (2017) pasien lebih banyak mengalami uremik pruritus pada 3 bulan pertama setelah hemodialisa bahkan mencapai 6 bulan berturut-turut sampai 12 bulan.

Menurut Narita et al (2006) penyebab uremik pruritus belum jelas diketahui tetapi ada beberapa faktor pencetus yang berbagai macam (multifaktor). Dalam pernyataan Kimata et al (2014) teori terbaru menemukan bahwa uremik pruritus dikaitkan akibat penurunan sistem imunitas tubuh, dalam penelitian ini usia lansia awal (46-55 tahun) dan lansia akhir (56-65 tahun) merupakan data mayoritas terjadinya uremik pruritus, hal ini dapat dikaitkan dengan usia lansia yang mengalami penurunan fungsi tubuh salah satunya penurunan daya tahan tubuh sehingga usia lansia lebih rentan terjadinya uremik pruritus, penelitian lain yang memiliki hasil yang sama dengan penelitian ini adalah pernyataan yang dikemukakan oleh Begger \& Steinhoff (2011) yang menyatakan bahwa usia lansia memiliki kaitan dengan pengembangan atau keparahan terjadinya uremik pruritus pada responden gagal ginjal kronik, tetapi tidak memiliki hasil yang sama dengan penelitian yang dilakukan oleh Szepietowski et al (2002) yang menyatakan bahwa usia tidak mempengaruhi terjadinya uremik pruritus.

Dalam beberapa penelitian ditemukan bahwa faktor jenis kelamin juga mempengaruhi terjadinya uremik pruritus. Dalam penelitian ini responden dengan jenis kelamin laki-laki lebih mayoritas mengalami uremik pruritus dibandingkan dengan perempuan dimana jenis kelamin telah dikaitkan dengan patogenesis uremik pruritus (Berger \& Steinhoff, 2011; Lin et al. 2011; Combs et al. 2015; Aval et al. 2018).

Beberapa faktor lain yang dapat memperberat terjadinya uremik pruritus adalah pasien yang mengalami penyakit penyerta seperti hipertensi dan diabetes melitus hal ini dikemukakan oleh Kimata et al (2014). Dalam penelitian ini mayoritas responden mengalami penyakit penyerta hipertensi dan diabetes melitus. Hal ini dapat terjadi dimana penyakit penyerta itu sendiri atau obat-obatan yang dikonsumsi menjadi pemicu terjadinyakeparahan uremik pruritus (Mettang et al., 2013; Nakamoto et al,. 2019) meskipun dalam pernyataan Narita et al. (2006) bahwa penyakit penyerta seperti diabetes dan hipertensi bukan merupakan faktor independen yang dapat memperberat terjadinya uremik pruritus

Dampak dari uremik pruritus mayoritas responden mengalami gangguan tidur yang diukur melalui kuesioner 5-D Itch scale yang terdiri dari lima domain pertanyaan beserta lokasi gatal yang dirasakan oleh responden dalam pernyataan yang disampaikan responden membuat sulit tidur dan terkadang terbangun dimalam hari sebanyak 46,9\% hal ini sesuai dengan pernyataan Mathur (2010); Combs et al. (2015) bahwa pasien yang mengalami uremik pruritus akan mengalami gangguan tidur.

Penelitian yang dilakukan Kimbali et al. (2016) yang menyatakan bahwa secara umum uremik pruritus dapat mengganggu tidur sehingga menghambat atau mengganggu aktivitas bekerja karena kurangnya kebutuhan tidur. Dalam penelitian ini mayoritas responden tidak bekerja dengan persentase $51,3 \%$. Penelitian ini sejalan dengan penelitian Lin et al. (2011) bahwa uremik pruritus dapat mempengaruhi kegiatan hubungan sosial dan produktivitas kerja pernyataan lain dalam penelitian Simonsen et al. (2017) menyatakan bahwa responden yang mengalami uremik pruritus mengganggu aktivitas sosial dan kualitas hidup sehingga dapat mencetus peningkatan kematian.

Uremik pruritus yang dirasakan oleh responden dalam penelitian dengan durasi rasa gatal dalam waktu 2 minggu terakhir mayoritas merasakan gatal $<6$ jam/hari sebanyak $49 \%$ dan nilai yang lain seperti durasi tertinggi 18-23 jam/hari dirasakan responden sebanyak 4,1\% dengan intensitas rasa gatal mayoritas dalam kategori sedang, perkembangan rasa gatal selama dua minggu terakhir oleh responden mayoritas dirasakan tingkat uremik pruritus (rasa gatal) semakin parah dengan nilai persentase $44,9 \%$ hal ini dikaitkan karena uremik pruritus berfluktuasi,dari waktu ke waktu meskipun pruritus yang dirasakan bersifat stabil tetapi akan timbul secara episodik karena uremik pruritus terjadi di seluruh aliran darah atau bersifat sistemik akibat dari 
penumpukan urea dimana hal ini terjadi karena ginjal tidak mampu menyaring, membersihkan darah dari zat asing yang masuk ke dalam tubuh melalui konsumsi makanan dan minuman sehari-hari serta tidak mampu diekskresi secara maksimal. Hal ini sejalan dengan yang dinyatakan oleh Combs et al (2015); Berger \& Stainhoff (2011) bahwa uremik pruritus yang dirasakan pada responden hampir setiap hari secara terputus-putus atau dirasakan hilang timbul.

Lokasi rasa gatal bervariasi tetapi yang paling sering dialami oleh responden umumnya dalam penelitian ini yaitu pada area atau bagian punggung dengan hasil yang di dapatkan sebanyak $77,6 \%$ tetapi area bokong dan abdomen juga menjadi area yang sering. Area punggung menjadi area yang paling umum terjadi karena punggung merupakan area yang yang paling luas dan sering mengalami penekanan dan memiliki hasil yang sama dengan pernyataan Berger \& Steinhoff (2011); Simonsen et al (2017).

\section{Simpulan}

Dalam penelitian ini ditemukan ada beberapa hal yang menjadi penyebab terjadinya pruritus uremik meskipun sudah dilakukan tindakan hemodialisa, selain akibat rusaknya ginjal yang sudah bersifat progresive usia lansia, jenis kelamin, penyakit penyerta yang ada pada pasien gagal ginjal kronik, menjalani hemodialisa sudah lebih dari setahun yang berdampak dalam kehidupan pasien seperti gangguan tidur adalah dampak yang paling sering terjadi pada pasien gagal ginjal kronik sehingga mengganggu proses kehidupan dan menurunkan kualitas hidup pasien.

\section{Referensi}

Abdelghfar, S. Z., Elsebae, H. A., Elhadry, S. M., \& Hassan, A. A. Effect of Aromatherapy on Uremic Pruritus among Patients Undergoing Hemodialysis. (2017). IOSR Journal of Nursing a nd Health Science (IOSR-JNHS e-ISSN: 2320 1959.p- ISSN: 2320-1940 Volume 6, Issue 2 Ver. VIII (Mar. - Apr. 2017), PP 22-30 www.iosrjournals.org

Aval, S. B., Ravanshad, Y., Azarfar, A., Mehrad-Majd, H., Torabi, S., \&Ravanshad, S. (2018).A Systematic Review and Meta-analysis of Using Acupuncture and Acupressure for Uremic Pruritus. Iranian journal of kidney diseases, 12(2), 78.

Berger, T. G., \& Steinhoff, M. (2011, June). Pruritus and renal failure. In Seminars in cutaneous medicine and surgery (Vol. 30, No. 2, p. 99). NIH Public Access.

Combs, S. A., Teixeira, J. P., \&Germain, M. J. (2015, July).Pruritus in kidney disease.In Seminars in nephrology (Vol. 35, No. 4, pp. 383-391). WB Saunders.

Cürcani, M., \& Tan, M. (2014).The effect of aromatherapy on haemodialysis patients' pruritus. Journal of clinical nursing, 23(23-24), 3356-3365.

Elman, S., Hynan, L. S., Gabriel, V., \& Mayo, M. J. (2010). The 5-D itch scale: a new measure of pruritus. British Journal of Dermatology, 162(3), 587-593.

Germain, M. J. (2017). Uremic pruritus: an itch with ominous consequences. American journal of nephrology, 46(6), 448-450.

Kimata, N., Fuller, D. S., Saito, A., Akizawa, T., Fukuhara, S., Pisoni, R. L., ...\&Akiba, T. (2014). Pruritus in hemodialysis patients: Results from the $\mathrm{J}$ apanese $\mathrm{D}$ ialysis $\mathrm{O}$ utcomes and $\mathrm{P}$ ractice $\mathrm{P}$ atterns $\mathrm{S}$ tudy (JDOPPS). Hemodialysis International, 18(3), 657-667.

Kimball, A. B., Edson-Heredia, E., Zhu, B., Guo, J., Maeda-Chubachi, T., Shen, W., \& Bianchi, M. T. (2016). Understanding the Relationship Between Pruritus Severity and Work Productivity in Patients With Moderate-to-Severe Psoriasis:

Lin, T. C., Lai, Y. H., Guo, S. E., Liu, C. F., Tsai, J. C., Guo, H. R., \& Hsu, H. T. (2012). Baby oil therapy for uremic pruritus in haemodialysis patients. Journal of clinical nursing, 21(1-2), 139-148.

Mathur, V. S., Lindberg, J., Germain, M., Block, G., Tumlin, J., Smith, M., ... \& ITCH National Registry Investigators. (2010). A longitudinal study of uremic pruritus in hemodialysis patients. Clinical Journal of the American Society of Nephrology, 5(8), 1410-1419

Mettang, T., \& Kremer, A. E. (2015).Uremic pruritus. Kidney International, 87 (84), 685-691.

Nakamoto, H., Kobayashi, T., Noguchi, T., Kusano, T., Ashitani, K., Imaeda, H., \&Maezono, M. (2019). Prevalence and Severity of Itching in Patients with End-Stage Renal Disease: Treatment with Nalfurafine Hydrochloride. Blood purification, 47(2), 45-49.

Nakhaee, S., Nasiri, A., Waghei, Y., \&Morshedi, J. (2015). Comparison of Avenasativa, vinegar, and hydroxyzine for uremic pruritus of hemodialysis patients: a crossover randomized clinical trial. Iranian journal of kidney diseases, 9(4), 316.

Narita, I., Alchi, B., Omori, K., Sato, F., Ajiro, J., Saga, D., ...\&Akazawa, K. (2006). Etiology and prognostic significance of severe uremic pruritus in chronic hemodialysis patients. Kidney international, 69(9), 1626-1632.

National Institutes of Health.(2012). Kidney disease statistics for the United States. Washington: NHI. 
Simonsen, E., Komenda, P., Lerner, B., Askin, N., Bohm, C., Shaw, J., ...\&Rigatto, C. (2017). Treatment of uremic pruritus: a systematic review. American Journal of Kidney Diseases, 70(5), 638-655.

Smeltzer, Bare, Hinkle \& Cheever. (2010). Text BookOf Medical SurgicalNursing. Edisi 12. Lippincott Williams \& Wilkins

Szepietowski, J. C., Sikora, M., Kusztal, M., Salomon, J., Magott, M., \& Szepietowski, T. (2002). Uremic pruritus: a clinical study of maintenance hemodialysis patients. The Journal of dermatology, 29(10), 621-627.

Tarp, H., Bonde-Petersen, M., \& Finderup, J. (2017). Patients in Haemodialysis Experienced Uraemic Pruritus as a Dual Phenomenon. Journal of renalcare, $43(1), 21-28$. 